\title{
Um Luís da Silva qualquer: a inadaptação à cidade moderna em Angústia, de Graciliano Ramos
}

\author{
Natália Ubirajara Silva*
}

\begin{abstract}
Resumo: o presente trabalho apresenta uma análise do romance Angústia, de Graciliano Ramos, centrada no narrador-protagonista, Luís da Silva. À luz do conflito entre cidade moderna e campo, estudamos a inadaptação de Luís aos códigos da cidade (Maceió). Também abordamos brevemente o papel do escritor na modernidade e a relação de Luís da Silva com a personagem Julião Tavares.
\end{abstract}

Palavras-chave: Graciliano Ramos; cidade; modernidade; flâneur.

\begin{abstract}
:. this paper presents an analysis of the novel Angústia, by Graciliano Ramos, which is centered in the narrator-protagonist, Luís da Silva. Through the conflict between the modern city and the country, we studied the unsuitability of Luís for the urban codes of Maceió. It also briefly approaches the writer's role in modern days and the relationship between the characters Luís da Silva and Julião Tavares.
\end{abstract}

Keywords: Graciliano Ramos; city; modernity; flâneur.

O romance Angústia, publicado em 1936, apresenta ao leitor diversos aspectos a serem explorados. Neste trabalho, exploraremos como o narrador-protagonista, Luís da Silva, se situa na cidade moderna. De origem rural, Luís demonstra, ao longo do romance, extremo desajuste com relação aos códigos urbanos, sem encontrar um lugar próprio. Seu conflito com a modernidade materializa-se na figura de um jovem rico, Julião Tavares, totalmente inserido e bem-sucedido no ambiente moderno.

Homem de 35 anos que se auto-define como tímido e feio, Luis da Silva é morador do centro de Maceió (Alagoas). Além de ser funcionário público do Tesouro, trabalha, à noite, em um jornal. Tendo acertado casamento com Marina (vizinha mais pobre do que ele), é trocado por Julião Tavares, rapaz próspero. Luís passa a ter obsessão pela ex-noiva, perseguindo-a. Ao descobrir que ela está grávida de Julião, Luís estrangula o rival, pendura o corpo em uma árvore - para simular suicídio - e retorna à sua casa, entrando em um estado de devaneio que só será remediado por meio da escrita (a escrita do próprio romance, Angústia).

\footnotetext{
* Mestranda do Pós-Graduação em Letras - UFRGS
} 
Como dissemos, Luís vivia no centro de Maceió. Porém, na realidade, nascera e crescera na fazenda de seu avô, Trajano Pereira de Aquino Cavalcante e Silva. Sua partida para a capital, a exemplo de muitos outros nordestinos, deu-se em razão da decadência do sistema patriarcal baseado no latifúndio. Essa degradação das velhas estruturas é revelada, na memória de Luís, pelas sombras do passado: Trajano (avô), Camilo Pereira da Silva (pai), Germana (avó), Quitéria (empregada, ex-escrava) e outras personagens da fazenda. A representação dessa crise não se dá de maneira direta e objetiva. É aos poucos, a cada episódio aparentemente sem maior significação, que se pode perceber a deterioração do poder do latifúndio: era o Mestre Domingos, ex-escravo, quem arrastava o velho Trajano completamente bêbado de volta à casa. Após a morte do patriarca, a família de Luís parte para uma vila, primeiro movimento migratório na trajetória do narrador. É na vila que Luís da Silva tem acesso à leitura, com o mestre Antônio Justino, e decide partir para a cidade grande, cujo crescimento é inversamente proporcional à decadência do campo:

[...] Sabia onde ficavam o Rio de Janeiro, São Paulo, Minas, lugares que me atraíam, que atraem a minha raça vagabunda e queimada pela seca. Resolvi desertar para uma dessas terras distantes. Abandonei a vila, com uma trouxa debaixo do braço e os livros da escola (RAMOS, 2003, p. 20)

A ida à cidade é, portanto, uma deserção, fuga de um mundo degradado. No meio rural nordestino, os valores eram basicamente os mesmos da sociedade escravocrata: engenho, patriarca, escravos (basta lembrarmos da empregada de Trajano, Quitéria). Nesse mundo, o senhor é respeitado e temido, autoridade máxima. As velhas estruturas precisam ser mantidas, pois garantem o domínio do senhor e seus descendentes. Nas primeiras décadas do século XX, porém, esse mundo já se encontra em declínio, principalmente com a criação de usinas e também - e é essa a questão que se apresenta em Angústia - com o desenvolvimento das cidades, num movimento intenso de modernização do país.

Com a derrocada da aristocracia rural, o horizonte que se apresenta é a cidade grande, em que os códigos são outros, os da modernidade, regida pelo capital (moda, "burguesia", competição, individualismo). Esse mundo, “constantemente em mudança” (BERMAN, 2007, p. 12), opõe-se frontalmente ao contexto rural, pois não se baseia na manutenção das velhas estruturas. Como assinala Berman, a cidade moderna é um ambiente que

[...] promete aventura, poder, alegria, crescimento, autotransformação e transformação das coisas em redor - mas ao mesmo tempo ameaça destruir tudo o que temos, tudo que o sabemos, tudo o que somos [...] pode-se dizer que a modernidade une a espécie humana. Porém, é uma unidade paradoxal, uma unidade de desunidade: ela nos despeja a todos num turbilhão de permanente desintegração e mudança, de luta e contradição, de ambigüidade e angústia. Ser moderno é fazer parte de um universo no qual, como disse Marx, "tudo que é sólido desmancha no ar" (BERMAN, 2007, p. 24) 
É nesse turbilhão que é lançado Luís da Silva. Essa mudança de ambiente, porém, não se dá sem percalços. Chegando a Maceió, Luís mergulha de maneira brusca na modernidade, sem ter ainda abandonado os velhos códigos patriarcais. $\mathrm{O}$ primeiro choque entre esses mundos diversos se dá na busca por um emprego. No tempo em que morava na vila, Luís teve vários tipos de ocupação: mestre de meninos, serviço militar e revisor. Já na cidade grande, o sistema é outro: "indignidades, curvaturas, mentiras, [...] caça ao pistolão" (RAMOS, 2003, p. 24). Humilhando-se, consegue se empregar e se mudar para a pensão de D. Aurora, na periferia de Maceió. De origem a que podemos chamar aristocrática, Luís teve de se curvar e mendigar por comida e emprego na cidade; de classe dominante, passa a dominado. Ele aponta para essa decadência com tristeza e desalento: "Como sou diferente do meu avô!" (RAMOS, 2003, p. 25), "Tudo agora era diferente [...] Como a cidade me afastara de meus avós!” (p. 97-98). A deterioração da antiga classe dominante se dá na própria redução do nome de família, uma metáfora da decadência: o avô se chamava Trajano Pereira de Aquino Cavalcante e Silva; o pai, Camilo Pereira da Silva; o narrador é apenas Luís da Silva, redução que acaba por colocá-lo ao nível do cidadão comum, um "Zé Ninguém” em meio à multidão urbana, "um cidadão como os outros, um diminuto cidadão que vai para o trabalho maçador, um Luís da Silva qualquer” (RAMOS, 2003, p. 19).

Na cidade, a memória do campo se torna refúgio e resgate de um tempo perdido. Luís sente nostalgia de sua infância. Para ele, todos os males estão no presente; diz não ter havido sofrimentos no tempo em que vivia na fazenda do avô. No entanto, há consciência de que o passado não pode ser recuperado: "Entro no quarto, procuro um refúgio no passado. Mas não me posso esconder inteiramente nele. Não sou o que era naquele tempo. Falta-me tranqüilidade, falta-me inocência, estou feito um molambo que a cidade puiu demais e sujou" (RAMOS, 2003, p. 18). A cidade provoca uma transformação negativa em Luís, ressaltando a sua decadência. A degradação que começara a ser vivida no campo se concretiza plenamente no ambiente urbano. De descendente da aristocracia rural, Luís da Silva se torna um molambo, um “níquel social” (RAMOS, 2003, p. 35).

Esse choque entre mundos diversos gera intenso desconforto no narrador-protagonista. Ao longo da narrativa, torna-se patente a inadaptabilidade de Luís aos códigos da cidade. Vivendo em si o choque entre realidades conflitantes, Luís permanece na cidade não por capricho, moda ou escolha, mas por questão de sobrevivência. Em dado momento, ele afirma não lhe ser necessário ter automóvel ou rádio, pois se contentaria com uma casa de palha e cama de varas, "como Quitéria, como o velho Trajano e Camilo Pereira da Silva" (RAMOS, 2003, p. 153). A vida que verdadeiramente lhe apraz é a de sua infância rural, talvez 
justamente por ser um tempo a que já não pode mais regressar. O passado é a única oportunidade de fuga do presente (no qual o narrador não vê saída e oportunidades, onde é ninguém), e é por isso que Luís, mais uma vez, vê o tempo de sua infância como ideal.

Ao perceber que o passado é um tempo que não pode ser resgatado (cf. RAMOS, 2003, p. 18), Luís teve que procurar formas de sobreviver em meio à lógica moderna. Nesse sentido, podemos recorrer à afirmação de Willi Bolle quanto ao flâneur. Para Bolle, o flâneur, que em seus primórdios estava ligado ao ócio feudal, não é mais aquele que deambula pela cidade para observá-la. Na sociedade regida pelo capital, "sem investimentos, o dinheiro acaba, e o flâneur-rentier se vê ameaçado de degradação [...] ele teve de se assimilar à sociedade" (BOLLE, 1994, p. 376). Como aponta Rattier,

O flâneur que havíamos encontrado pelas ruas e calçadas e em frente às vitrinas das lojas, esse tipo ínfimo, insignificante [...] se transformou agora em agricultor, produtor de vinho, fabricante de linho, refinador de açúcar, industrialista do aço (apud BENJAMIN, 1985b, p. 82)

Luís da Silva vive esse conflito: é um observador da cidade moderna (saindo do café, olha as vitrinas e cartazes) mas, mesmo inadaptado a essa lógica, precisa garantir o seu sustento. A mesma situação aparece na reflexão que Luís faz ao olhar para um guarda de trânsito:

Onde estariam os descendentes de Amaro vaqueiro? Talvez o guarda civil do relógio oficial fosse um deles [...] Os campos estão desertos, o gado enegreceu com o carrapato, os homens valentes pegaram o rifle, amarraram a cartucheira na cintura. O guarda-civil do relógio oficial veio para a cidade e arranjou emprego. É um sujeito magro como eu, civilizado como eu. Se houver barulho na rua, ele apita. Se houver greve nas fábricas e lhe mandarem atirar contra os grevistas, atira tremendo. As greves acabam. E ele voltará para a chateação do ponto, magro, triste. É pouco mais ou menos como eu (RAMOS, 2003, p. 153)

O guarda e Luís, assim como todos os oriundos do interior, chegam à cidade e lá precisam reconstruir seu lugar social, "começar do zero". A antiga classe dominante é agora um “percevejo social” (RAMOS, 2003, p. 22), premida a encontrar formas de sobrevivência num mundo hostil. Sem dominar os códigos da cidade, resta, para eles, uma existência mesquinha, como guarda de trânsito ou, no caso de Luís, escritor de textos por encomenda. Ainda imbuído de valores antigos, mas vivendo em meio à modernidade crescente, Luís aumenta sua renda de funcionário público vendendo a sua arte. O salário obtido na repartição era suprido com a venda de poemas e artigos encomendados - a serem publicados pelo jornal em que Luís trabalhava. A narrativa apresenta já em seu início a inquietação do narrador quanto a esse aspecto:

Certos lugares que me davam prazer tornaram-se odiosos. Passo diante de uma livraria, olho com desgosto as vitrinas, tenho a impressão de que se acham ali pessoas, exibindo títulos e preços nos rostos, vendendo-se. É uma espécie de prostituição. Um sujeito chega, atenta, encolhendo os ombros ou estirando o beiço, naqueles desconhecidos que se amontoam por detrás do vidro. Outro larga uma opinião à-toa. Basbaques escutam, saem. E os autores, 
resignados, mostram as letras e os algarismos, oferecendo-se como as mulheres da Rua da Lama (RAMOS, 2003, p. 5)

Luís da Silva revela, no trecho acima, a condição do escritor na cidade moderna: vendedor e prostituto, comparado às mulheres da Rua da Lama (antiga zona de prostituição no centro de Maceió). Nesse sentido, o discurso de Luís se aproxima da visão que Baudelaire tinha acerca de sua poesia, "musa que pode ser comprada" (apud BENJAMIN, 1985a, p. 64); em outras palavras, a literatura é mercadoria. Essa dessacralização do fazer literário ocorre devido à inserção do poeta na sociedade baseada no capital. Como aponta Benjamin, o produtor de cultura, na modernidade, precisa se inserir no mercado; ele "pensa que é para dar uma olhada nele; na verdade, porém, já para encontrar um comprador" (BENJAMIN, 1985b, p. 39).

A inadaptabilidade de Luís à cidade moderna também é desvelada pelo contraste entre ele e seu rival, Julião Tavares. O jovem rico, da elite urbana, representa, na cidade, a autoridade que o Trajano Pereira de Aquino Cavalcante e Silva tinha no latifúndio. O avô de Luís fazia filhos nas escravas - e isso só tem fim com a abolição, início do seu processo de decadência; Julião, da elite citadina, continua essa "tradição" de explorar e fazer filhos na classe subalterna (engravida Marina, e antes já sofrera processos por defloramento). A transferência da autoridade de Trajano a Julião pode ser percebida por meio do vestuário, analisado por Luís "A roupa do intruso era bem feita, os sapatos brilhavam. Baixei a cabeça. Os meus sapatos novos estavam mal engraxados, cobertos de poeira [...] Camilo Pereira da Silva andava emproado como um galo, e as rosetas das esporas de ferro tilintavam" (RAMOS, 2003, p. 72-73). Ao analisar as roupas e sapatos do rival, a memória de Luís resgata a figura do pai, num tempo em que sua família detinha autoridade. Na cidade, não é o sapato com esporas de seu pai que Luís usa. Seus sapatos sujos são a imagem do processo de decadência que viveu e encarna. É Julião quem, no espaço urbano, impõe respeito e é constantemente bajulado: "Transeuntes sorriam ao dono da mão curta de unhas brunidas. Eu notava com raiva aqueles sorrisos. Porque tanta subserviência nas caras abertas? Julião Tavares, patriota e orador, não prestava para nada" (RAMOS, 2003, p. 174). Em meio a todas essas deferências, o neto do patriarca rural passa despercebido. Tem, entretanto, a percepção de que a superioridade de Julião é arbitrária e que, na verdade, por mais "percevejo social” que seja, também tem condições - talvez até mais do que seu rival - de ser autoridade.

Julião Tavares também é um espelho invertido de Luís da Silva em outros contextos. Como vimos anteriormente, este tem que vender seu talento para sobreviver na cidade moderna. Seus produtos eram sonetos, discursos políticos e notícias falaciosas sobre 
acontecimentos locais. "É o que sei fazer: alinhar adjetivos, doces ou amargos, em conformidade com a encomenda" (RAMOS, 2003, p. 43). Esse aspecto, porém, não lhe é confortável, sendo possível perceber conflitos de consciência ao longo da narrativa:

Que miséria! Escrevendo constantemente, o espinhaço doído, as ventas em cima do papel, lá se foram toda a força e todo o ânimo. De que me servia aquela verbiagem? - "Escreva assim, seu Luís". Seu Luís obedecia. - "Escreva assado, seu Luís". Seu Luís arrumava no papel as idéias e os interesses dos outros. Que miséria! (RAMOS, 2003, p. 138)

Sua ocupação ressaltava a distância que havia entre ele e Trajano: escrever para os outros era uma outra forma de negação do passado. Tornando-se escritor de textos encomendados, faz o que lhe mandam, e não a sua própria vontade. A frase "Escreva assim, seu Luís" percorre toda a narrativa, comprovando haver desconforto com sua subserviência na escrita. Julião, por sua vez, é também um escritor. Contudo, diferentemente de Luís, é um exibicionista, tanto escrita quanto oralmente: "linguagem arrevesada, muitos adjetivos, pensamento nenhum" (RAMOS, 2003, p. 40). O narrador, porém, já começando a saber operar na lógica da cidade, desvela: Julião "um talento notável, porque juntou dinheiro" (RAMOS, 2003, p. 47). De família rica, é representativo da elite sócio-econômica que aspira a ser também elite intelectual. Travou conhecimento com Luís em uma festa de arte no Instituto Histórico, ao empurrá-lo acidentalmente, e desde esse dia passa a freqüentar sua casa. Há um distanciamento evidente entre ambos e também entre os outros visitantes (Moisés, comunista; Pimentel, jornalista; seu Ivo, que vivia perambulando pela região). O narrador, ao reavaliar sua trajetória, menciona que sua antipatia por Julião e o conseqüente sentimento de ódio surgiram já na primeira visita deste à sua casa. Vemos, dessa forma, que a ojeriza de Luís pelo "literato e bacharel" (RAMOS, 2003, p. 41) de linguagem arrevesada não se deve apenas ao envolvimento deste com Marina, mas a algo mais, como veremos em seguida. A gravidez de Marina é apenas o estopim que o leva às vias de fato, mas o ódio já estava latente há muito tempo.

A que poderíamos atribuir esse ódio de Luís da Silva para com Julião Tavares? Como dissemos anteriormente, o rapaz rico é seu espelho invertido fazendo-o sentir-se diminuído:

Gordo, bem vestido, perfumado e falador, tão falador que ficávamos enjoados com as lorotas dele. Não podíamos ser amigos. Em primeiro lugar o homem era bacharel, o que nos distanciava. [...]

Além disso Julião Tavares tinha educação diferente da nossa. Vestia casaca, freqüentava os bailes da Associação Comercial e era amável em demasia [...] Pois foram tolices assim que aquele tipo nos veio impingir. Horrível. Diante dele eu me sentia estúpido (RAMOS, 2003, p. 45)

Podemos questionar até que ponto Julião seria esse ser tão abominável quanto o narrador nos apresenta. Embora sendo pernóstico, tem interesse em literatura e artes, além de 
tentar entrar no grupo de intelectuais (Luís, Pimentel e Moisés). O narrador parece superdimensionar os elementos negativos da personalidade de Julião Tavares, demonstrando um profundo recalque pelo bacharel rico ser tudo o que ele não era, e ter tudo o que ele não tinha. Ao espreitar o rival antes de assassiná-lo, Luís se questiona: "Para que seguir o homem odioso que tinha tudo, mulheres, cigarros?” (RAMOS, 2003, p. 182). Essa era a imagem que tinha de Julião: usurpador da autoridade que devia ser sua, escritor medíocre recebedor de honras, elite econômica, homem desejado por Marina. Era por tudo isso que ele deveria ser eliminado.

Nesse sentido, é possível realizar uma aproximação entre o confronto Julião versus Luís e a análise que Berman (2007) faz acerca do Homem do Subterrâneo, personagem das Notas do subterrâneo, de Dostoievski. No episódio apresentado por Berman, o "Homem do Subterrâneo", reles funcionário público de São Petersburgo, tenta começar uma briga com um oficial e, para isso, se posta em seu caminho; o oficial, porém, sequer toma conhecimento de sua existência, desviando-o do caminho com a mão. O funcionário passa "vários anos de angústia exaustiva" (BERMAN, 2007, p. 259) tramando - e desejando - um novo encontro com o oficial, com o firme propósito de, ao encontrá-lo, postar-se à sua frente sem desviar, forçando uma trombada. O Homem vê nesse choque um gesto de emancipação, um modo de efetivar seu reconhecimento. Nessa cena primordial de conflito entre oficial aristocrático (autoridade) e funcionário pobre, o funcionário tem profundo "anseio por um choque frontal, um encontro explosivo - mesmo que venha a ser vítima desse encontro [...] ele vibra com a possibilidade de encrenca" (BERMAN, 2007, p. 260), pois isso implicaria ser reconhecido, ser visto, "existir".

Assim como o Homem do Subterrâneo de Dostoievski, o Luís da Silva de Graciliano Ramos não é percebido e, sentindo-se diminuído, cede espaço (num primeiro momento). $\mathrm{O}$ narrador tem o costume de ir a um café da Rua do Sol (rua do centro de Maceió, próxima à sua casa) e observar os freqüentadores, mas lá não há espaço efetivo para ele. Havia no café, a exemplo da sociedade, uma profunda separação entre bem-sucedidos e pobres-diabos: "Tipos bestas. Ficam dias inteiros fuxicando nos cafés e preguiçando, indecentes. Quando avisto essa cambada, encolho-me, colo-me às paredes como um rato assustado. Como um rato, exatamente" (RAMOS, 2003, p. 6). A atitude de Luís é paradoxal, pois ao mesmo tempo em que se encolhe perante o outro, deseja ser visto por ele. É o que acontece no bonde: "Eu encolhia-me, reduzia-me e, em caso de necessidade, sentava-me com uma das nádegas" (RAMOS, 2003, p. 176). Por outro lado, "agradavam-me os passageiros que me pisavam os pés, nos bondes, e se voltavam, atenciosos: - Perdão, perdão. Faz favor de desculpar" 
(RAMOS, 2003, p. 23). Apesar de se encolher, ansiava por um encontro; quer ser, como o Homem do Subterrâneo, reconhecido, embora nada faça para sair de sua condição de "criaturinha insignificante, um percevejo social, acanhado" (RAMOS, 2003, p. 22), que não consegue vencer a invisibilidade e indiferença inerentes à cidade moderna. Nela, os habitantes são "[...] milhares de figurinhas insignificantes. Eu era uma figurinha insignificante e mexiame com cuidado para não molestar as outras" (RAMOS, 2003, p. 222).

Luís percebe não só essa insignificância, mas também a inexistência de um lugar para ele na cidade - em quaisquer que sejam as camadas. Nesse sentido, demonstra grande lucidez na percepção dos códigos urbanos, talvez justamente por não estar integrado a ela. Segundo Bolle, essa é uma característica típica do flâneur: situado na classe média, ele pode ser instrumento para a "missão de reconhecimento do labirinto da Modernidade" (BOLLE, 1994, p. 372). Luís da Silva cumpre esse papel de diagnóstico da sociedade moderna. "À medida que se urbaniza, [...] compreende as mazelas que afetam a saúde da cidade. A origem rural dálhe distância necessária para perceber o que de dentro não se vê" (SCHÜLER, 1993, p. 42). Ao perambular pela Rua do Sol e observar o café, Luís desvela os códigos urbanos:

[...] E gosto do café, passo lá uma hora por dia, olhando as caras. Há o grupo dos médicos, o dos advogados, o dos comerciantes, o dos funcionários públicos, o dos literatos. [...] A mesa a que me sento fica ao pé da vitrina dos cigarros. É um lugar incômodo: as pessoas que entram e as que saem empurram-me as pernas. Contudo não poderia sentar-me dois passos adiante, porque às seis horas da tarde estão lá os desembargadores (RAMOS, 2003, p. 21)

Essa consciência do não-pertencimento não se restringe à relação com a alta esfera da sociedade. Também não há identificação com os mais pobres, aqueles que foram totalmente excluídos do sistema. Nos arrabaldes, face obscura da cidade, estavam os que eram obrigados a ver a modernização pelo "lado de fora": os trabalhadores, que sustentavam com sua mão-deobra a classe dominante. Ao entrar em uma bodega na Ladeira de Santa Cruz (relativamente afastada do centro de Maceió), Luís se sente um forasteiro, pois era letrado, um intelectual: "os vagabundos não tinham confiança em mim” (RAMOS, 2003, p. 109); a barreira invisível que havia entre eles era a cultura. Nem sua mendicância passada criava identificação: "Eu queria [...] dar a entender que também era vagabundo, que tinha [...] dormido nos bancos dos passeios, curtido fome. Não me tomariam a sério. Viam um sujeito de modos corretos [...] A literatura nos afastou" (RAMOS, 2003, p. 110). Logo após o assassinato de Julião Tavares, há outro momento de encontro entre Luís e os que vivem a modernidade no "lado de fora":

Estava ali um vagabundo, que acordou com a minha chegada [...]

- Boa noite. [...] Faz favor de me dar um cigarro?

$\mathrm{O}$ homem remexeu-se:

- Hum!

[...]

- Muito obrigado. Sinto muito dar-lhe incômodo. 


\section{$-\mathrm{Hem}$ ?}

Esta exclamação mostrou-me que o homem havia percebido em mim um animal diferente dele [...] Olhei a minha roupa. Estava imunda [...] Mas usava palavras de gente bem vestida [...]

- Dorme aqui sempre?

[...] Impossível qualquer aproximação. $\mathrm{O}$ isolamento em companhia de uma pessoa era mais opressivo que a solidão completa (RAMOS, 2003, p. 195-196)

Luís, embora tenha vivido na rua e não pertença à elite econômica, não é compreendido pelo mendigo. Seu anseio era se integrar, fosse com quem fosse. Após o diálogo transcrito acima, ele se ressente com o vagabundo, dizendo que nunca fora tão grosseiro. Encontrar um igual é algo que não se mostra possível. Vemos, assim, que Luís não se enquadra na cidade moderna. Ele se encontra no entre-lugar: nem totalmente inserido na sociedade (como Julião Tavares), nem à parte dela (como o mendigo e os freqüentadores da bodega).

Há momentos em que o narrador confessa o desejo de se tornar um igual, confrontar o ambiente hostil: "Levanto-me. Sou um bípede, é preciso ter a dignidade dos bípedes. Um cachorro como Julião Tavares andar empertigado, eu curvar-me para a terra, como um bicho! Desentorto o espinhaço" (RAMOS, 2003, p. 114). Esse confronto com a lógica da cidade começa a se materializar, aos poucos, na figura de Julião Tavares. Trazendo à tona a memória da decadência da família Silva e sendo tudo aquilo que o narrador, na cidade, não consegue ser, Julião se torna o alvo eleito para que Luís, a exemplo do Homem do Subterrâneo, planejasse uma "trombada". O assassinato é uma tentativa frustrada de enfrentamento: "Era evidente que Julião Tavares devia morrer, Não procurei investigar as razões desta necessidade. Ela se impunha” (RAMOS, 2003, p. 135). Matar um homem com a projeção de Julião poderia ser um meio de igualar-se a ele em reconhecimento, já que “[...] Um criminoso de morte era diferente, merecia consideração" (RAMOS, 2003, p. 144) e "Fazia receio matar um sujeito importante como Julião Tavares" (RAMOS, 2003, p. 154).

$\mathrm{Na}$ noite em que se põe a perseguir Julião (que havia ido à casa de uma nova amante), Luís segue o rival num misto de atração e repulsa. Favorecido pela escuridão, o estrangula. Esse assassinato só poderia ter acontecido nessas condições: "Se me achasse diante de Julião Tavares, à luz do dia [...] Sentir-me-ia miúdo e perturbado, os músculos se relaxariam, a coluna vertebral se inclinaria para a frente [...] Afastar-me-ia precipitadamente, como um bicho inferior" (RAMOS, 2003, p. 183). À luz do dia, Luís não teria coragem suficiente para efetivar o enfrentamento. A noite é o ambiente próprio para esse ataque frontal. Nela, dominador e dominado não se distinguem. Por apenas um instante, Luís se sente um igual, e é aí que ele parte para a ação. Nesse momento, não se vinga apenas da pessoa de Julião; o rival é, na realidade, representativo de toda a humilhação a que a cidade o tem submetido: 
Então eu era nada? [...] Eu era um cachorro, um ninguém. - "É-me conveniente escrever um artigo, seu Luís.” Eu escrevia. E pronto, nem muito obrigado. Um Julião Tavares me voltava as costas e me ignorava. Nas redações, na repartição, no bonde, eu era um trouxa, um infeliz, amarrado. Mas ali, na estrada deserta, voltar-me as costas como a um cachorro sem dentes! Não. Donde vinha aquela grandeza? Porque aquela segurança? Eu era um homem. Ali era um homem (RAMOS, 2003, p. 185)

Como vemos na citação acima, - "um Julião Tavares" -, a vítima é e ao mesmo tempo não é o rival. Mais do que a um indivíduo, o assassinato significa eliminar a supremacia de todo aquele que sabe manejar a lógica da cidade. Luís vê no homicídio a vitória sobre todas as humilhações sofridas até então, seja no jornal, no Tesouro ou no bonde. Sua tomada de decisão está marcada: "Não." É nesse momento que Luís toma o propósito de não mais se deixar encurvar diante dos que o oprimiam. Ao enrolar a corda no pescoço de Julião, sente-se outro homem, distante do medíocre funcionário da repartição que era até então, e o que ele chama de "deslumbramento" e "alegria enorme" (RAMOS, 2003, p. 186) preenche seu ser. A perseguição e o estrangulamento servem, momentaneamente, de liberação: "Tinham-me enganado. Em trinta e cinco anos, haviam-me convencido de que só me podia mexer pela vontade dos outros [...] tudo virou fumaça. Julião Tavares estrebuchava" (RAMOS, 2003, p.186). Para o Homem do Subterrâneo de Dostoievski, o reconhecimento se daria na trombada; para Luís, no estrangulamento do rival. É essa a sua vingança contra a cidade moderna.

Alguns instantes após o homicídio, porém, a dura realidade começa a ser percebida: “[...] veio-me a certeza de que me havia tornado velho e impotente. - Inútil, tudo inútil” (RAMOS, 2003, p. 189). Contemplando o cadáver de Julião, Luís se dá conta da inutilidade de seu ato e começa a ter medo das consequiências (captura e aprisionamento). Para Schmidt, "As sensações imediatas ao crime são logo substituídas por medo e culpa" (1993, p. 61). Cremos, entretanto, que Luís não sente culpa pelo assassinato; o que ele tem é uma consciência aguda da inutilidade de seu ato, tendo noção de que seu ato foi uma liberação fugaz. No dia seguinte, estaria novamente amarrado às peias de antes, à vida medíocre de sempre: "Um funcionário. Pus-me a rir como um idiota. Continuaria a escrever informações, a bater no teclado da máquina, a redigir artigos bestas" (RAMOS, 2003, p. 211). Para garantir sua liberdade, Luís teve que ocultar seu feito "heróico" e se manter, mais uma vez, preso ao sistema da cidade.

No caminho de retorno à sua casa, Luís entra em um total atordoamento, que é desejado por ele: "Uma felicidade estar com febre" (RAMOS, 2003, p. 203); "Estava doente, ia piorar, e isto me alegrava. Deitar-me, dormir, o pensamento embaralhar-se longe daquelas porcarias" (RAMOS, 2003, p. 204). Como vemos, ele quer entrar em estado de delírio para 
fugir dos fatos e apagar da memória não só o crime, mas toda a sua trajetória na cidade. Luís passa cerca de um mês com a vista embaçada, rumores nos ouvidos, febre e devaneios (mas tudo depois de cuidadosamente desfiar as roupas usadas na hora do assassinato...). A recuperação se dá no primeiro capítulo. Para Schüler,

\begin{abstract}
a desorganização das últimas páginas provocada pela afetividade perturbada é um momento importante na passagem do discurso estereotipado e oco ao discurso inventivo. A reconstrução requer a demolição do rejeitado. Passada a vertigem, as mãos se colocam a serviço da invenção (SCHÜLER, 1993, p. 43)
\end{abstract}

A perturbação na qual Luís se encontra no final da narrativa seria, portanto, uma preparação para a libertação por meio da escrita. Ao escrever sua própria história, ele se liberta da escrita encomendada, ditada pelos padrões da cidade moderna. Agora, cria um texto seu, a partir de sua posição, a partir de suas inquietações. Mesmo ainda em meio à crise e inadaptação, tem a capacidade de verbalizá-las - e é aí que, de certa forma, consegue se encontrar. Segundo Schüler (1993, p. 39), Luís "é o primeiro angustiado numa sociedade em que a moeda costura todas as relações [...] E é o primeiro a escrever". Ele não é, pois, um alienado. Utilizando-se de sua inadaptação para tomar a palavra, demonstra autonomia e percepção aguçada de seu meio, vencendo sua pequenez e se tornando superior à sociedade em que vive.

\title{
Referências
}

BENJAMIN, Walter. A Paris do Segundo Império em Baudelaire. In: Walter Benjamin: sociologia. São Paulo: Ática, 1985a. p. 44-122

Paris, capital do século XIX. In: Walter Benjamin: sociologia. São Paulo: Ática, 1985b, p. 30-43

BERMAN, Marshall. Tudo que é sólido desmancha no ar. São Paulo: Companhia das Letras, 2007.

BOLLE, Willi. A metrópole: palco do flâneur. In: . Fisiognomia da metrópole moderna. São Paulo: Editora da Universidade de São Paulo, 1994. p. 365-400

RAMOS, Graciliano. Angústia. Rio de Janeiro: O Globo, 2003.

SCHMIDT, Simone. Itinerário de uma angústia. In: Cadernos Porto\&Vírgula: Graciliano Ramos. Porto Alegre: Secretaria Municipal da Cultura, 1993. p. 58-62

SCHÜLER, Donaldo. Angústia, romance e salto. In: Cadernos Porto\&Vírgula: Graciliano Ramos. Porto Alegre: Secretaria Municipal da Cultura, 1993. p. 39-44 